\title{
Aggregation and deformability of erythrocytes in primary open-angle glaucoma (POAG); the assessment of arterial hypertension
}

\author{
Katarzyna Michalska-Małecka ${ }^{\mathrm{a}, *}$ and Ludmiła Słowińska-Łożyńska ${ }^{\mathrm{b}}$ \\ ${ }^{a}$ The Clinic of Ophthalmology of the Silesian Medical University, Clinic Hospital, Katowice, Poland \\ ${ }^{\mathrm{b}}$ The Chair and Department of Biophysics, Faculty of Medicine of the Silesian Medical University, Zabrze \\ Rokitnica, Poland
}

\begin{abstract}
Primary open-angle glaucoma (POAG) is one of the most common types of glaucoma. Glaucoma is a progressive neuropathy of the optic nerve with characteristic visual area disorders. The aim of this study was to assess the correlations between rheological parameters of blood and other parameters such as: intraocular pressure, visual acuity, angular breadth of the aqueous fluid eluvium, visual area and arterial hypertension.

The examined group was comprised of 54 patients with POAG. Out of this group two subgroups was separated: I subgroup of 24 patients without hypertensive and II subgroup of 30 patients with chronic hypertensive disease. The control group was comprised of 40 healthy subjects. Erythrocyte aggregation and deformability analysis were determined using LORCA.

From the results we concluded that rheological disorders such as enhanced erythrocyte aggregation or significantly decreased erythrocyte deformability occur in patients with POAG. Additionally, it revealed a significant relation between the duration of hypertension and an increased erythrocyte aggregation index $(r=+0.27 p<0.005)$ along with decreased deformability $(r=-0.37$ $p<0.001)$, where the decrease in deformability correlated with the severity of hypertonic retinal angiopathy $(r=-0.30 p<0.05)$. All these disorders may result in decreased blood flow to the optic nerve, which contributes towards the development of neuropathy.
\end{abstract}

Keywords: Primary open-angle glaucoma (POAG), deformability of erythrocytes, aggregation of erythrocytes, LORCA, arterial hypertension

\section{Introduction}

Primary open-angle glaucoma (POAG) is one of the most common types of glaucoma. The course of this disease is hidden, so a patient is not aware of having glaucoma until his/her sight is damaged. The World Health Organization (WHO) has acknowledged glaucoma to be social disease. Worldwide there are about 68 million people who suffer from glaucoma and over 7 million who are blind as a result of this disease [18].

\footnotetext{
*Corresponding author: Katarzyna Michalska-Małecka, Sybirakow Street 18, 44-203 Rybnik, Poland. Tel.: +48 600064150 ; Fax: +48 32 4329100; E-mail: kasia@marat.com.pl.
} 
Glaucoma is a progressive neuropathy of the optic nerve with characteristic visual area disorders. As known from the literature, many so-called glaucoma risk factors affect the development of glaucoma's neuropathy $[4,18]$. The major factors are:

- a high intraocular pressure,

- vascular factors connected with the impairment of eyeball hemodynamics such as: low blood pressure, night hypotonia, arterial hypotension, vasospastic syndrome, vascular changes in the course of diabetes, migraine or abnormal blood rheological parameters.

Age, family genetic background, myopia or race can also affect the development of glaucoma. Despite many risk factors, the mechanism leading to glaucoma is always the same - ischemia of the optic nerve triggering a cascade of complex biochemical reactions resulting in nerve cell atrophy $[22,25]$.

The aim of this study was to assess the correlations between the blood rheological parameters in patients with glaucoma regarding chronic hypertensive disease and other parameters such as: intraocular pressure, visual acuity, angular breadth of the aqueous fluid eluvium, visual area and arterial hypertension.

\section{Material}

\subsection{Examined group}

The examined group was comprised of 54 patients ( 14 men and 40 women; mean age: $68.7 \pm 8.1$ years) with POAG selected during medical examinations in the Department of Ophthalmology, Medical University of Silesia, Katowice. The study protocol was accepted by the Ethical Committee of Medical University of Silesia (NN-2-252/07) and all participants agreed to participate and signed an informed consent.

\subsection{Subgroups}

I. Out of the group of the patients with POAG, a subgroup I of 24 patients ( 9 men and 15 women; mean age: $68.1 \pm 9.2$ years) without arterial hypertensive disease was separated. The average value of systolic blood pressure on the day of exam was $137 \pm 15 \mathrm{mmHg}$; diastolic pressure was $87 \pm 10 \mathrm{mmHg}$.

II. Out of the group of the patients with POAG, a subgroup II of 30 patients ( 5 men and 25 women; mean age: $69.3 \pm 7.3$ years) with chronic arterial hypertensive disease was separated. Mean time of treatment for hypertension was 14.5 years (range: 3-50 years). Hypertonic retinal angiopathy the effect of hypertension in both eyes, was recognized in 25 patients. Average value for systolic tension on the day of the exam was $151 \pm 23 \mathrm{mmHg}$; diastolic tension was $89 \pm 12 \mathrm{mmHg}$, whereby it should be noted that patients were taking antihypertensive medication.

\subsection{Control group}

The control group was comprised of 40 non-smokers with no chronic hypertensive disease (14 men and 26 women; mean age: $42.1 \pm 9.5$ years). 


\section{Methods}

\subsection{Blood sampling}

Blood samples for rheological tests were taken from anticubital vein using K2EDTA as anticoagulant. All patients had fasted before exams. All parameters were tested within 2-4 hours of blood sampling.

\subsection{Erythrocyte aggregation and deformability analysis}

The analysis of erythrocyte aggregation and deformability was performed using a Laser-assisted Optical Rotational Cell Analyzer LORCA (Mechatronics, Netherlands) at a stable temperature of $37^{\circ} \mathrm{C}$. Erythrocyte aggregation was determined after a fifteen-minute blood oxygenation in a ratio of $1: 3$ with the use of a roller bank. The following parameters were calculated:

- aggregation amplitude (Amp),

- half time $t_{1 / 2}$,

- aggregation index (AI).

To determine erythrocyte deformability $25 \mu \mathrm{l}$ of blood and $5 \mathrm{ml}$ of isosmotic solution of PVP in phosphate buffered saline were used. The elongation index (EI), which is a parameter of deformability of erythrocytes undergoing shearing, was calculated for three chosen shear stresses: $\tau=18.49 \mathrm{~Pa}$, $\tau=33.20 \mathrm{~Pa}, \tau=60.03 \mathrm{~Pa}$.

\subsection{Blood and plasma viscosity determination}

Blood and plasma viscosity were determined using a Brookfield DV-II+ Cone/Plate Viscometer (Brookfield Engineering Laboratories, USA) at a stable temperature of $37^{\circ} \mathrm{C}$. The shear rate was: $150 \mathrm{~s}^{-1}$ for blood and $900 \mathrm{~s}^{-1}$ for plasma viscosity.

\subsection{Arterial pressure measurements}

In all patients systolic and diastolic blood pressure was taken in a recumbent position after a five-minute rest using the Riva-Rocci method. Out of the three arterial pressure measurements, the mean value was taken into consideration.

\subsection{Ophthalmological examination}

Ophthalmological examination included: visual acuity, intraocular pressure, filtration angular breadth, visual area and hypertonic retinal angiopathy.

\subsection{Statistical analysis}

The Kolnognov-Smirnov test was carried out for all variables in order to test the normal distribution. The differences between the parameters obtained for the examined groups were evaluated using variance analysis and the $t$-Student Test. Person's correlation coefficients $(r)$ were calculated after giving numerical 
ranges to ophthalmological parameters. Differences were considered to be statistically significant if $p<0.05$.

\section{Results and Discussion}

Baseline characteristics of all study groups have been presented in Table 1. POAG group, I Subgroup without hypertension, II Subgroup with hypertension no differences were observed in age, prevalence of ischemic heart disease, migraine headaches and hematocrit. No statisticall differences in hematocrit levels were observed between all study groups and the control group.

Compared to the I Subgroup without hypertension, the II Subgroup with hypertension had more subjects with diabetes mellitues type II and more subjects with an elevated body-mass-index BMI, which often accompanies diabetes [15]. Many researchers believe that secondary glaucoma is influenced by diabetes but in our study subjects with secondary glaucoma were excluded.

The aggregation parameters obtained in the group with POAG, and the POAG's subgroups with and without chronic arterial hypertension and the control group have been shown in Tables 2 and 4 . The differences between the group with POAG and the control group were statistically significant (Table 2). In comparison with the control group, in the group with POAG the mean aggregation amplitude Amp was $11 \%$ lower, the mean half time $\mathrm{t}_{1 / 2}$ was $21 \%$ shorter and the mean aggregation index AI was $9 \%$ higher. Differences in the aggregation parameters in subgroups I and II were statistically significant compared to the control group (except Amp in subgroup I without hypertension) but the differences were greater between the control group versus subgroup II with hypertension (Table 4). This indicates an increase in power of erythrocyte chains in aggregates - reflected by the AI and Amp values - which requires higher

Table 1

Baseline characteristics of all study groups

\begin{tabular}{|c|c|c|c|c|}
\hline & $\begin{array}{c}\text { POAG group } \\
\quad n=54\end{array}$ & $\begin{array}{l}\text { I Subgroup without } \\
\text { hypertension } n=24\end{array}$ & $\begin{array}{c}\text { II Subgroup with } \\
\text { hypertension } n=30\end{array}$ & $\begin{array}{c}\text { control group } \\
n=40\end{array}$ \\
\hline Arterial hypertension ${ }^{\circ}$ & $30(56 \%)$ & 0 & $30(100 \%)$ & 0 \\
\hline Diabetes mellitus type $\mathrm{II}^{\circ}$ & $18(33 \%)$ & $5(21 \%)$ & $13(43 \%)$ & 0 \\
\hline Ischemic heart disease $^{\circ}$ & $16(30 \%)$ & $5(21 \%)$ & $11(37 \%)$ & 0 \\
\hline Migraine headaches ${ }^{\circ}$ & $8(15 \%)$ & $3(13 \%)$ & $5(17 \%)$ & 0 \\
\hline Smokers of tobacco $^{\circ}$ & $20(37 \%)$ & $10(42 \%)$ & $10(33 \%)$ & 0 \\
\hline Body mass index & $27.8 \pm 6.2$ & $24.9 \pm 3.8$ & $30.1 \pm 6.8$ & $26.1 \pm 3.0$ \\
\hline BMI $\left(\mathrm{kg} / \mathrm{m}^{2}\right)^{\prime}$ & $\begin{array}{c}(17.7 \div 52.4) \\
22.4 \%\end{array}$ & $\begin{array}{c}(17.7 \div 33.9) \\
15.3 \%\end{array}$ & $\begin{array}{c}(18.6 \div 52.4) \\
22,6 \%\end{array}$ & $\begin{array}{c}(21.0 \div 34.3) \\
11.4 \%\end{array}$ \\
\hline Age (years)" & $\begin{array}{c}69 \pm 8 \\
(49 \div 82) \\
11.8 \%\end{array}$ & $\begin{array}{c}68 \pm 9 \\
(49 \div 81) \\
13.5 \%\end{array}$ & $\begin{array}{c}69 \pm 7 \\
(55 \div 82) \\
10.5 \%\end{array}$ & $\begin{array}{c}42 \pm 9 \\
(30 \div 63) \\
22.6 \%\end{array}$ \\
\hline Hematocrit $(\%)^{\prime}$ & $\begin{array}{c}40 \pm 4 \\
(34 \div 50) \\
8.6 \%\end{array}$ & $\begin{array}{c}40 \pm 4 \\
(34 \div 47) \\
8.9 \%\end{array}$ & $\begin{array}{c}41 \pm 4 \\
(34 \div 50) \\
8.5 \%\end{array}$ & $\begin{array}{c}43 \pm 3 \\
(38 \div 447) \\
6.9 \%\end{array}$ \\
\hline
\end{tabular}

${ }^{\circ}$ data is presented as the number of patients and the per cent ratio relative to the size of the respective group.

"data is presented as average \pm standard deviation, range of values, coefficient of variation in $\%$. 
Table 2

The statistical analysis of erythrocyte aggregation's parameters

\begin{tabular}{lccc}
\hline & $\begin{array}{c}\text { POAG group } \\
n=54\end{array}$ & $\begin{array}{c}\text { Control group } \\
n=40\end{array}$ & $\begin{array}{c}\text { Significance } \\
\text { POAG/control }\end{array}$ \\
\hline Aggregation amplitude & $21.8 \pm 3.8$ & $24.0 \pm 2.8$ & \\
Amp (au) & $(12.4 \div 29.6)$ & $(18.5 \div 29.0)$ & $p<0.001$ \\
& $17.3 \%$ & $11.5 \%$ & \\
Aggregation half-time & $2.1 \pm 0.7$ & $2.6 \pm 0.9$ & \\
$\mathrm{t}_{1 / 2}(\mathrm{~s})$ & $(0.9 \div 3.6)$ & $(1.4 \div 5.2)$ & $p<0.001$ \\
& $32.2 \%$ & $33.4 \%$ & \\
Aggregation index & $65.3 \pm 6.4$ & $60.0 \pm 7.0$ & \\
AI $(\%)$ & $(52.1 \div 77.2)$ & $(43.3 \div 72.2)$ & $p<0.001$ \\
& $9.7 \%$ & $11.7 \%$ & \\
\hline
\end{tabular}

au - arbitrary units of LORCA device. Data is presented as average \pm standard deviation, range of values, coefficient of variation in $\%$.

Table 3

The statistical analysis of erythrocyte deformability

\begin{tabular}{lccc}
\hline & POAG group & Control group & $\begin{array}{c}\text { Significance } \\
n=54\end{array}$ \\
& $n=40$ & POAG/control \\
\hline Elongation index EI $(\%)$ & $337 \pm 98$ & $535 \pm 84$ & \\
for $\tau=18.49 \mathrm{~Pa}$ & $(127 \div 555)$ & $(362 \div 604)$ & $p<0.001$ \\
& $29.2 \%$ & $15.7 \%$ & \\
Elongation index EI $(\%)$ & $373 \pm 103$ & $571 \pm 82$ & \\
for $\tau=33.20 \mathrm{~Pa}$ & $(153 \div 590)$ & $(402 \div 604)$ & $p<0.001$ \\
& $27.5 \%$ & $14.3 \%$ & \\
Elongation index EI $(\%)$ & $406 \pm 103$ & $601 \pm 78$ & \\
$\quad$ for $\tau=60.03 \mathrm{~Pa}$ & $(190 \div 618)$ & $(439 \div 655)$ & $p<0.001$ \\
& $25.4 \%$ & $12.9 \%$ & \\
\hline
\end{tabular}

Data is presented as average \pm standard deviation, range of values, coefficient of variation in $\%, \tau-$ shear stress.

shear stresses to break them down as well as the acceleration of the aggregation phenomenon - reflected by the values of $\mathrm{t}_{1 / 2}$.

The effects of erythrocyte aggregation on blood flow are complex [20,21]. On one hand, the presence of aggregates is beneficial for blood flow due to the effect of shear stress on blood vessel walls (endothelium) which results in the production of nitric oxide (NO) vasodilator, which in turn leads to the dilation of the blood vessel and an increased blood flow. On the other hand, in pathological cases, e.g. in the presence of hypertension, the endothelium does not react correctly, and in this situation a rise in erythrocyte aggregation causes a rise in blood viscosity resulting in the enhanced residence of the blood flow, which leads to a major reduction of the flow of blood or even hemostasis [19]. 
Table 4

The statistical analysis of erythrocyte aggregation's parameters in subgroup of POAG group

\begin{tabular}{lcccc}
\hline & $\begin{array}{c}\text { I Subgroup without } \\
\text { hypertensive } n=24\end{array}$ & $\begin{array}{c}\text { Significance } \\
\text { I/control }\end{array}$ & $\begin{array}{c}\text { II Subgroup with } \\
\text { hypertensive } n=30\end{array}$ & $\begin{array}{c}\text { Significance } \\
\text { II/control }\end{array}$ \\
\hline Aggregation amplitude & $22.3 \pm 4.5$ & & $21.4 \pm 3.1$ & \\
Amp [au] & $(12.4 \div 29.6)$ & ns & $(16.6 \div 26.7)$ & $p<0.001$ \\
& $20.3 \%$ & & $14.3 \%$ & \\
Aggregation half-time & $2.0 \pm 0.6$ & & $2.1 \pm 0.7$ & \\
$\mathrm{t}_{1 / 2}[\mathrm{~s}]$ & $(0.9 \div 3.4)$ & $p<0.01$ & $(1.2 \div 3.6)$ & $p<0.05$ \\
& $30.5 \%$ & & $33.8 \%$ & \\
Aggregation index & $65.7 \pm 6.1$ & & $65.0 \pm 6.6$ & \\
AI [\%] & $(54.1 \div 77.2)$ & $p<0.005$ & $(52.1 \div 74.3)$ & $p<0.005$ \\
& $9.3 \%$ & & $10.2 \%$ & \\
\hline
\end{tabular}

$\mathrm{au}$ - arbitrary units of LORCA device. Data is presented as average \pm standard deviation, range of values, coefficient of variation in $\%$.

Table 5

The statistical analysis of erythrocyte deformability in subgroup of POAG group

\begin{tabular}{lcccc}
\hline & $\begin{array}{c}\text { I Subgroup without } \\
\text { hypertensive } n=24\end{array}$ & $\begin{array}{c}\text { Significance } \\
\text { I/control }\end{array}$ & $\begin{array}{c}\text { II Subgroup with } \\
\text { hypertensive } n=30\end{array}$ & $\begin{array}{c}\text { Significance } \\
\text { II/control }\end{array}$ \\
\hline Elongation index EI [\%] & $307 \pm 90$ & & $364 \pm 100$ & \\
for $\tau=18.49 \mathrm{~Pa}$ & $(127 \div 471)$ & $p<0.001$ & $(181 \div 555)$ & $p<0.001$ \\
& $29.2 \%$ & & $27.6 \%$ & \\
Elongation index EI [\%] & $342 \pm 95$ & & $398 \pm 103$ & \\
for $\tau=33.20 \mathrm{~Pa}$ & $(153 \div 515)$ & $p<0.001$ & $(205 \div 590)$ & $p<0.001$ \\
& $27.8 \%$ & & $26.0 \%$ & \\
Elongation index EI [\%] & $376 \pm 97$ & & $430 \pm 103$ & \\
for $\tau=60.03 \mathrm{~Pa}$ & $(190 \div 543)$ & $p<0.001$ & $(232 \div 618)$ & $p<0.001$ \\
& $25.9 \%$ & & $24.0 \%$ & \\
\end{tabular}

Data is presented as average \pm standard deviation, range of values, coefficient of variation in $\%, \tau$ - shear stress.

A comparison of the two subgroups showed no significant statisticall differences in aggregation parameters, but significant differences $(p<0.05)$ were seen in deformability of erythrocytes at shear stress 18.49 $\mathrm{Pa}$ and 33.20 $\mathrm{Pa}$, but not at shear stress $60.03 \mathrm{~Pa}$.

A comparison of the elongation indices of the group with POAG and both its subgroups, performed at different shear stresses, with the indices of the control group (Tables 3 and 5) showed a considerable and statistically significant decrease of around $35 \%$.

Good erythrocyte deformability is needed to transport oxygen and carbon dioxide for regular tissue perfusion. The decreased deformability not only diminishes tissue oxygenation [2] but also makes erythrocyte life span shorter [26].

In the full POAG group significant positive correlation $(r=+0.23 p<0.05)$ between the plasma viscosity and the ranges of visual area of both eyes was found. This indicates that the enhanced residence of the 
blood flow resulting from a rise in plasma viscosity can cause visual acuity disorders. The bigger defects in the visual area, the worse visual acuity was diagnosed in the examined patients $(r=+0.42 p<0.001)$. Moreover, enhanced erythrocyte deformability was connected with a better outflow of the aqueous fluid reflected by the values of the measured filtration angular breadth, which was then confirmed by the positive range correlation $(r=+0.28 p<0.005)$. It seems possible that better fed cells work better.

The separation of the subgroup with hypertensive disease out of the group with POAG allowed to calculating many statistically significant correlations. One of glaucoma's most important parameters, the intraocular pressure summed for both eyes, showed a positive correlation $(r=+0.27 p<0.005)$ with the hypertensive disease duration. Moreover, the positive correlation between the intraocular pressure and visual acuity disorders $(r=+0.44 p<0.001)$ as well as the increase in AI $(r=+0.27 p<0.05)$ was found. The values of the systolic and diastolic blood pressure, taken on the day of the test, correlated positively with visual acuity disorders $(r=+0.46 p<0.001$ and $r=+0.36 p<0.001$ respectively). There was also a positive correlation between the both eyes' visual area disorders and the systolic and diastolic pressure $(r=+0.44 p<0.001$ and $r=+0.29 p<0.05$ respectively). The lower aggregation amplitude Amp, the higher systolic and diastolic pressures were measured in the examined patients $(r=-0.37 p<0.001$ and $r=-0.33$ $p<0.005$ respectively). However, the aggregation index AI increased along with the increase in both these pressures $(r=+0.27 p<0.05$ and $r=+0.42 p<0.001$ respectively). The elongation index EI of erythrocyte deformability diminished when the hypertensive disease duration got longer $(r=-0.37 p<0.001)$ and visual area disorders appeared $(r=-0.31 p<0.01)$. There was a positive correlation between EI and the filtration angular breadth $(r=+0.30 p<0.05)$. The better erythrocyte deformability, the better fluid flow was in the examined patients. Hypertonic retinal angiopathy connected with changes in the vascular endothelium resulting from hypertensive disease correlated negatively with the elongation indexes EI of erythrocyte deformability $(r=-0.30 p<0.05)$. Angiopathic changes were affected by the hypertensive disease duration $(r=+0.31 p<0.01)$ and the enhanced blood viscosity $(r=+0.45 p<0.001)$. The more extensive the angiopathy, the less outflow of the aqueous fluid was in the examined patients $(r=-0.40$ $p<0.001$ ).

In the subgroup with hypertensive disease a great number of significant correlations between rheological and ophthalmological parameters probably resulted from the pathogen that was arterial hypertension.

Epidemiologic investigations carried out in 2002-2003 in Poland [3] showed that in a population of 18645 patients with glaucoma at first place among risk factors was arterial hypertension in 55\% of the patients but arterial hypotension was placed on sixth position. Arterial hypertension not only causes an increase in the flow on the optic papillitis, but also transfers the mechanism of autoregulation on a higher level, which means that the physiologic decrease of arterial pressure during the night dreaming crosses the threshold of the compensatory autoregulation ability $[5,9,17]$. There was a correlation between the visual area disorders and the night decrease of arterial pressure in the patients with POAG and hypertensive disease. Hypotensive drugs which patients take before going to sleep also significantly affect the night arterial pressure decrease, which requires better cooperation between ophthalmologists and other physicians.

Many tests carried out to assess the significance of the vascular blood flow in the head of the optic nerve indicated that the flow of blood in the neuroretinal ring was significantly less in the patients with glaucoma of the normal intraocular pressure than those with increased pressure as well as those in the control group $[10,13]$. These findings were also confirmed by investigations $[7,8]$ which showed the additional correlation between the flow of blood in the head of the optic nerve and the mean value of arterial pressure. There was no such correlation in the control group. In the study [1] strong positive correlation between the arterial and intraocular pressure was found. Moreover, besides the correlation 
between the pulsation flow parameters and the intraocular pressure, the correlation between parameters characteristic for visual area disorders and the average thickness layers of neurofibrils were found, which showed that besides reduction, the blood flow instability also affects the development of glaucoma's neuropathy $[12,23]$.

Relative little attention was given to the significance of blood rheological parameters in the pathogenesis of glaucoma. Blood viscosity responsible for reduction of the blood flow is a crucial determinant of the flow of blood through vessels. The enhanced blood viscosity was diagnosed in patients with glaucoma and the enhanced intraocular pressure as well as those with glaucoma and the normal values of the intraocular pressure parameters [14, 24]. As is known, erythrocyte aggregation is responsible for blood viscosity of low shear stresses, whereas erythrocyte deformability affects blood viscosity of high shear stresses.

In his research Hamard et al. [11] showed an increase in the flow of blood through capillary vessels in the head of the optic nerve and a higher ability to erythrocyte aggregation. However, there was no correlation between both these parameters.

In this study the significant correlations between the erythrocyte aggregation parameters and the intraocular and arterial pressure were shown only in the subgroup with POAG and hypertensive disease.

In his lecture on hemorheological aspects in eye diseases, Foulds [6] mentioned a decrease in erythrocyte deformability in patients with glaucoma compared with a control group, but the result was not significant. Recent studies confirmed significantly the erythrocyte deformability decrease [16].

\section{Conclusion}

From the results of this study, it can be concluded that rheological disorders such as enhanced erythrocyte aggregation or significantly decreased erythrocyte deformability occur in patients with POAG. Additionally, it revealed a significant relation between the duration of hypertension and an increased erythrocyte aggregation index along with decreased deformability, where the decrease in deformability correlated with the severity of hypertonic retinal angiopathy. All these disorders may result in decreased blood flow to the optic nerve, which contributes towards the development of neuropathy.

\section{References}

[1] L. Bonomi, S. Babighian, M. Bonadimani, S. Perfetti, P. Brusini, P. Bernardi, S. Coser, M. De Concini, P. Cumer, M. Pedrotti, G. Totolo and M. Carli, Correlation between glaucoma and vascular factors and circumstances leadin to the diagnosis of glaucoma, Acta Ophthalmol Scand Suppl 232(78) (2000), 34-35.

[2] G. Cicco and A. Pirrelli, Red blood cell (RBC) deformability, RBC aggregability and tissue oxygenation in hypertension, Clin Hemorheol Microcirc 21(3-4) (1999), 169-177.

[3] J. Czajkowski and M. Pilas-Pomykalska, Występowanie naczyniowych czynników ryzyka w polskiej populacji chorych na jaskrę- badania epidemiologiczne z lat 2002-2003. Wyniki badań ankietowych 18645 chorych. Okulistyka 2 (2005) 3-7.

[4] European Glaucoma Society. Terminology and guidelines for glaucoma. 2nd Edition, Italy, 2003.

[5] J. Flammer, Glaucoma a guide for patients. An introduction for care-providers. A reference for quick information. Verlag Hans Huber. Bern. Göttingen. Toronto. Seattle, 2001.

[6] W.S. Foulds, 50th BOWMAN LECTURE: Blood is thicker than water. Some haemorheological aspects of ocular disease, Eye 1 (1987), 343-363.

[7] G. Fuchsjager-Mayrl, B. Wally, M. Georgopoulos, G. Rainer, K. Kircher, W. Buehl, T. Amoako-Mensah, H.G. Eichler, C. Vass and L. Schmetterer, Ocular blood flow and systemic blood pressure in patients with primary open-angle glaucoma and ocular hypertension, Invest Ophthalmol Vis Sci 45 (2004), 834-839. 
[8] D. Gherghel, S. Orgul, K. Gugleta, M. Gekkieva and J. Flammer, Relation between ocular perfusion pressure and retrobulbar blood flow in patients with glaucoma with progressive damage, Am J Ophthalmol 130 (2000), 597-605.

[9] J.E. Grunwald, J. Piltz, S.M. Hariprasad, J. Dupont and M.G. Maguire, Optic nerve blood flow in glaucoma: Effect of systemic hypertension, Am J Ophthalmol 127 (1999), 516-522.

[10] A.S. Hafez, R.L. Bizzarro and M.R. Lesk, Evaluation of optic nerve head and peripapillary retinal blood flow in glaucoma patients, ocular hypertensives and normal subjects, Am J Ophthalmol 136 (2003), 1022-1031.

[11] P. Hamard, H. Hamard and J. Dufaux, Blood Flow Rate in the microvasculature of the optic nerve head in primary open angle glaucoma. A new approach, Surv Ophthalmol 38 (1994), S87-S94.

[12] J. Kerr, P. Nelson and C. O'Brien, A comparison of ocular blood flow in untreated primary open-angle glaucoma and ocular hypertension, Am J Ophthalmol 126 (1998), 42-51.

[13] J. Kerr, P. Nelson and C. O'Brien, Pulsatile ocular blood flow in primery open-angle glaucoma and ocular hypertension, Am J Ophthalmol 136 (2003), 1106-1113.

[14] J.H. Klaver, E.L. Greve, H. Goslinga, H.C. Geijssen and J.H. Heuvelmans, Blood and plasma viscosity measurements in patients with glaucoma, Br J Ophthalmol 69 (1985), 765-770.

[15] K. Koltai, G. Feler, G. Kesmarky, Z. Keszthelyi, L. Czopf and K. Toth, The effect of blood glucose levels on hemorheological parameters, platelet activation and aggregation in oral glucose tolerance tests, Clin Hemorheol Microcirc 35 (2006), 517-525.

[16] A. Mary, I. Serre, J.F. Brun, B. Arnaud and C. Bonne, Erythrocyte deformability measurements in patients with glaucoma, J Glaucoma 2 (1993), 155-157.

[17] S.D. Mc Leod, S.K. West, H.A. Quigley and J.L. Fozard, A longitudinal study of the relationship between intraocular pressure and blood pressure, Invest Ophthalmol Vis Sci 31 (1990), 2361-2366.

[18] S. Resnikoff, D. Pascolini, D. Etya'ale, I. Kocur, R. Pararajasegaram, G. Pokharel and S. Mariotti, Global data on visual impairment in the year 2002. Bulletin of World Health Organization 82 (2004), 844-851.

[19] R. Ross, The pathogenesis of atherosclerosis. An update, N Engl J Med 314 (1986), 488-491.

[20] B.Y. Salazar Vazquez, J. Martini, A. Chavez Negrete, A.G. Tsai, S. Forconi, P. Cabrales, P.C. Johnson and M. Intaglietta, Cardiovascular benefits in moderate increases of blood and plasma viscosity surpass those associated with lowering viscosity: Experimental and clinical evidence, Clin Hemorheol Microcirc 44 (2010), 75-85.

[21] B.Y. Salazar Vazquez, M.A. Salazar Vazquez, M.G. Jaquez, A.H. Bracho Huemoeller, M. Intaglietta and P. Cabrales, Blood pressure directly correlates with blood viscosity in diabetes type 1 children but not in normals, Clin Hemorheol Microcirc 44 (2010), 55-61.

[22] K.G. Schmidt, L.E. Pillunat and N.N. Osborne, Ischemia and hypoxia. An attempt to explain the different rates of retinal ganglion cell death in glaucoma, Ophtalmology 101 (2004), 1071-1075.

[23] D.R. Trew and S.E. Smith, Postural studies in pulsatile ocular blood flow: II Chronic open angle glaucoma, Br J Ophthalmol 75 (1991), 71-75.

[24] G.E. Trope, R.G. Salinas and M. Glynn, Blood viscosity in primary open-angle glaucoma, Can J Ophthalmol 22 (1987), 202-204.

[25] R.N. Weinreb, D.S. Friedman, R.D. Fechtner, G.A. Cioffi, A.L. Coleman, C.A. Girkin, J.M. Liebmann, K. Singh, M.R. Wilson, R. Wilson and W.B. Kannel, Risk assessment in the management of patients with ocular hypertension, $A m J$ Ophthalmol 138(3) (2004), 458-467.

[26] Z.Y. Wen, L.C. Song, Z.Y. Yan, Z.H. Lu, D.G. Sun, Y. Shi and S. Chien, An animal model to study erythrocyte, senescence with a narrow time window of erythrocyte production: Alterations in osmotic fragility and deformability of erythrocytes during their life span, Clin Hemorheol Microcirc 19(4) (1998), 299-306. 